\title{
Identifying The Barriers to Universal Cervical Length Screening For Preterm Birth Prevention at Tertiary Hospitals in Thailand-Healthcare Managers' Perspectives: Implementation Research
}

\author{
Vitaya Titapant \\ Mahidol University \\ Saifon Chawanpaiboon ( $\nabla$ saifon.cha@mahidol.ac.th ) \\ Mahidol University \\ Sanitra Anuwutnavin \\ Mahidol University \\ Attapol Kanjanapongporn \\ Mahidol University \\ Julaporn Pooliam \\ Mahidol University \\ Pimolphan Tangwiwat \\ Bureau of Health Promotion, Ministry of Public Health
}

\section{Research Article}

Keywords: Barriers, Healthcare Managers' perspective, Preterm birth prevention, Universal cervical length screening

Posted Date: November 8th, 2021

DOI: https://doi.org/10.21203/rs.3.rs-1022559/v1

License: (c) (i) This work is licensed under a Creative Commons Attribution 4.0 International License. Read Full License 


\section{Abstract}

Objective: To identify healthcare managers' perspectives on the barriers to implementing cervical length screening to prevent preterm births.

Materials and Methods: There were 3 phases of the study. In Phase I, 10 healthcare managers were interviewed. Phase II comprised questionnaire development and data validation. In Phase III, the questionnaire was administered to 40 participants, and responses were analysed.

Results: The questionnaire was completed by 40 obstetricians. Their average related work experience was $21.0 \pm 7.2(5-35)$ years; 39 (97.5\%) respondents also had healthcare management responsibilities at their respective hospitals. Most hospitals were reported to have enough obstetricians (31 cases, 77.5\%) and to be able to accurately perform cervical length measurements (22 cases, 55.0\%). However, no funding was allocated to universal cervical length screening (39 cases, 97.5\%). Most respondents believed that implementing universal screening, as per Ministry of Public Health policies, would prevent preterm births (28 cases, $70.0 \%$ ). Moreover, they suggested that hospital fees for cervical length measurements should be waived (34 cases, $85.0 \%$ ). Three main perceived barriers to universal screening at tertiary hospitals were identified. They were heavy obstetrician workloads ( 20 cases, $50.0 \%$ ); inadequate numbers of medical personnel ( 24 cases, $60.0 \%$ ); unbelieving of the screening test to prevent preterm birth (8 cases, $20 \%$ ) and lack of free drug support for preterm birth prevention in high-risk cases (29 cases, $72.5 \%)$.

Conclusions: The main obstacles to universal cervical length screening are heavy staff workloads and inadequate government funding for ultrasound scanning and hormone therapy. The healthcare managers do not believe that the universal cervical length screening can help to reduce preterm birth. These barriers could be removed by reducing unnecessary work and providing funding.

\section{Summary}

The barriers of universal cervical length screening are unnecessary work tasks of physician, unbelieving for the screening test and funding by relevant government agencies.

\section{Background}

A "preterm birth" is one that occurs before 37 weeks' gestation.(1) Pregnant women with preterm labour experience regular uterine contractions that may result in cervical progression and delivery of a stillborn or premature baby.(2) At least $10 \%$ of these women will deliver within 7 days of the onset of the contractions.(2) Preterm births are the most common cause of neonatal death, accounting for approximately 1.1 million premature deaths annually. (3) At the same time, the surviving infants are at high risk of developing diabetes and cardiovascular disease in adult life. $(4,5)$ Therefore, a reduction in preterm births in Thailand will contribute to lowering the mortality rate of newborns younger than 28 days 
of life and reducing the number of low-birth-weight (LBW) babies. A "low birth weight" has been defined by the World Health Organization as one that is below 2,500 g.(6)

In Thailand, as elsewhere, the primary cause of a low birth weight is premature birth.(7) A UNICEF study (6) reported that in the year 2015, there were 132 million live births worldwide, with $15.5 \%$ of those being LBW babies. In developed, developing and underdeveloped countries, the LBW rate was found to be $7 \%$, $16.5 \%$ and $18.6 \%$, respectively. As to Asia, the rate was $18.3 \%$, which was among the highest in the world. Southeast Asian countries had a rate of $11.6 \%$. In Thailand, newborns with a birth weight of $<2,500$ grams accounted for $9 \%$ of all live births in 2015.(6) The World Health Organization set a goal under its Global Nutrition Target to reduce the number of babies born with a low birth weight by $30 \%$. In Thailand's case, achieving that goal will mean that the rate for LBW babies, expressed as a percentage of live births, will fall from the current level of $9-6.3 \%$ by the year 2025.(7)

In Thailand, there are an estimated 15,000 cases of preterm births annually.(8) Expenditure on preterm neonatal hospital care has been calculated to be in the order of 170,000 Baht/case (US $\$ 5,312 /$ case), which equates to a total of 255,000,000 Baht/year (US $\$ 79,680,000 /$ year). These figures exclude the longterm care costs incurred following hospital discharge.(8)

Based on current evidence, the Society for Maternal-Fetal Medicine,(9) the American College of Obstetricians and Gynecologists,(10) and the National Institute for Health and Care Excellence(11) have stated that cervical length screening between 20-24 weeks of gestation can help to identify women at risk of preterm delivery. The International Federation of Gynaecology and Obstetrics has also recommended that the screening should be performed for all pregnant women.(12)

The pregnant women at risk of preterm delivery are those with a history of preterm birth or a cervical length of less than $1.5 \mathrm{~cm}$. Progesterone administration has been reported to prevent preterm birth,(13) and it was associated with a $34-43 \%$ reduction in preterm births (relative risk, 0.6 ; $95 \% \mathrm{Cl}, 0.4-0.9) .(14)$

According to the 2017 Ministry of Public Health policies for preventing preterm births in Thailand,(15) public health facilities are required to provide standardised and comprehensive maternal and child health services. This includes an efficient referral system for preterm birth prevention, a standardised quality of antenatal services, and screening for the risk of preterm delivery. According to the Ministry's policies, pregnant women at risk of preterm delivery should receive measures in the form of cervical screening or other such methods. Moreover, the women at risk should be encouraged to utilize the preventive methods that are made available to them in the public healthcare system. Finally, the Ministry's policies state that preterm babies should receive standardised care appropriate to the related delivery hospital's potential. (15)

The provision of universal cervical length screening is one of many Thai policies to prevent preterm births. It is recommended that screening be performed at the gestational age of 20-24 weeks. As pregnant women with a short cervix $(<25 \mathrm{~mm}$ ) have a high risk of preterm delivery, it is recommended that they be treated with micronised progesterone vaginal suppositories to prevent preterm delivery.(15) 
However, it is now around 4 years since those policies were introduced in Thailand. In the light of the present study's assessment, it is considered that the policies were not successfully implemented. Most pregnant Thai women still do not receive cervical length screening.

Consequently, the objective of this research was to identify the obstacles to performing the screening from the perspective of healthcare managers in the field. Armed with that information, efforts could be made to improve the related management systems and resources, where needed, to provide comprehensive preventive support to pregnant women and reduce the incidence of preterm births.

\section{Materials And Methods}

This was a prospective, descriptive, implementation study. Before its commencement, its protocol was approved by the Siriraj Ethics Committee, Faculty of Medicine Siriraj Hospital (Si 343/2562). The Thai Clinical Trials Registry number was TCTR20190813003.

This survey study utilised a questionnaire format. To ensure an adequately sized dataset, a proportion of the results of interest of $50 \%(P=.5)$, an estimation error of $\leq 5 \%$ and a $95 \%$ confidence level (type I error $=0.05,2$-sided) were used. The number of healthcare managers needing to be surveyed was calculated to be 40 .

The research was divided into three phases.

\section{Phase I: In-Depth Interviews}

The information collected in the initial phase covered four aspects: (1) general personal information; (2) context evaluation of the universal cervical length screening policy and the resources available to carry it out; (3) input evaluation of the benefits of performing cervical length measurements, the importance of universal screening, and the impact of executing universal screening; and (4) process evaluation of a universal cervical length measurement programme and its barriers.

Exploratory interviews were conducted with 10 healthcare managers from various hospitals who had been recruited for the study. Prior to the interviews, those individuals had expressed a willingness to participate in the research project and had been invited to discuss it in a private counselling room. After the project details had been described, the healthcare managers were given time to ask questions and consider whether they wished to formally enrol in the trial. They were advised that they could decline to participate in the research or withdraw from it at any stage if they so desired. Those who decided to volunteer as a research subject were asked to sign an informed consent form before being formally interviewed at length.

The 10 participants were asked for permission for the conversations and the structured interviews to be audio recorded. The subjects initially completed a personal information questionnaire. Several topics were then examined in-depth in a structured interview. The topics related to the policy of implementing 
cervical length measurement for preterm birth prevention, the availability of resources, and any ideas relevant to the implementation of universal screening and its barriers. The time from the commencement of the filling in of the questionnaire until the interview close was about 30 minutes. The data integrity of the research questions was later verified.

\section{Phase II: Development and Validation of the Questionnaire}

The data obtained from the questionnaire and the 10 in-depth interviews were analysed to determine the means and standard deviations. This enabled the questionnaire and interview questions to be refined. The revised questionnaire and interview questions were tested for validity and reliability before their use in the next phase.

\section{Phase III: Administration of the Questionnaire}

During the final study phase, the validated questionnaire was randomly given to 40 healthcare managers working in tertiary hospitals located throughout Thailand.

\section{Statistical Analysis}

Demographic data were summarised using descriptive statistics, and categorical data were presented as numbers and percentages. All the statistical analyses were performed using PASW Statistics for Windows (version 18.0; SPSS Inc., Chicago, IL, USA).

\section{Results}

The results covered four aspects: (1) general personal information; (2) context evaluation of the universal cervical length screening policy and the resources available to carry it out; (3) input evaluation of the benefits of performing cervical length measurements, the importance of universal screening, and the impact of executing universal screening; and (4) process evaluation of a universal cervical length measurement programme and its barriers.

\section{(1) General personal information}

The respondents' personal information is detailed in Table 1. Their average age was $50.2 \pm 5.6(38-60)$ years. All had medical degrees, and they had graduated on average $26.4 \pm 5.7$ (14-36) years previously. They had worked in obstetrics and gynaecology for an average of $21.0 \pm 7.2(5-35)$ years. The respondents had also been in leadership or supervisory roles for an average of 3 years. All were directly involved in the provision of medical services, and $90 \%$ had teaching responsibilities. Most of the hospitals in the study had an inpatient capacity exceeding 500 beds.

(2) Context evaluation of the universal cervical length screening policy and the resources available to carry it out

The context information on the tertiary hospitals included in the study is presented in Table 2. Forty percent of the tertiary hospitals had a policy of performing cervical length measurements to prevent 
preterm births. Almost all of the healthcare managers (39 cases, 97.5\%) were responsible for policymaking within their respective hospital settings. Most were of the opinion that the centrally located Maternal and Child Health Board (run by the Thai Ministry of Public Health) contributed by providing hormone support (namely, micronized progesterone vaginal soft-gel capsules) to prevent preterm births and supporting staff training for cervical length measurement (23 cases, 57.5\%). However, the majority opined that the Board had little active involvement in premature birth prevention ( 25 cases, $62.5 \%$ ). The key roles that hospital healthcare managers would like to see the Maternal and Child Health Board play are formulating national policies and providing district hospitals with the main operational plans to reduce the incidence of preterm births (32 cases, $80.0 \%$ ).

Table 3 summarises the availability of resources at the hospitals. Most hospitals were reported to have enough obstetricians (31 cases, $77.5 \%$ ). It was estimated that over $50 \%$ of the hospital obstetricians could accurately perform cervical length measurements (22 cases, $55.0 \%$ ) and were responsible for programmes promoting preterm birth prevention (32 cases, 80.0\%). However, in most cases, there was no funding to run such a project (39 cases, $97.5 \%$ ). Furthermore, the use of an ultrasound machine was considered sufficient for the project in many cases (20 cases, $50.0 \%$ ).

\section{(3) Input evaluation of the benefits of performing cervical length measurements, the importance of universal screening, and the impact of executing universal screening}

A tabulation of the assessments of the project inputs is given in Table 4. The healthcare managers recognised that preterm births are a major problem in almost all hospitals (39 cases, $97.5 \%$ ) and a very serious problem in most cases (23 cases, $57.5 \%$ ). While most hospital obstetricians were reported to be capable of performing vaginal ultrasound, they do not have certification approval (33 cases, $82.5 \%$ ). The healthcare managers considered that the ultrasound method is very useful ( 25 cases, $62.5 \%)$. A large minority opined that having a national, universal screening policy should prompt hospitals to carry out the related tasks either independently $(10 / 25$ cases, $40.0 \%)$ or in conjunction with other routine tasks (10/25 cases, $40.0 \%)$. The healthcare managers also believed that the policy would reduce premature births (29 cases, $72.5 \%$ ). In addition, the majority knew that a policy to perform universal cervical measurement for premature birth prevention was part of the 2017 policy guidelines of the Ministry of Public Health (29 cases, $72.5 \%$ ), and most agreed with that policy (18 cases, $62.1 \%$ ).

Table 5 lists the impacts of preterm births on pregnant women, family and on hospitals. Preterm births were reported to have a huge impact on the workloads of the relevant medical personnel (36 cases, $90.0 \%)$. Moreover, the healthcare managers indicated that preterm births result in much greater hospital expenses than otherwise (34 cases, 85.0\%) and the need for long-term hospital stays (37 cases, 92.5\%). In addition, the costs of caring for premature babies placed a high burden on most families (29 cases, $72.5 \%$ ), as did the costs of treating the associated medical problems (37 cases, $92.5 \%$; Table 5). This financial burden was reported to greatly affect the lifestyle and work of the parents (35 cases, $87.5 \%$ ). The healthcare managers also believed that the performance of universal screening in accordance with the Ministry of Public Health policy could prevent many preterm births (28 cases, $70.0 \%$ ). As well, they 
suggested that the hospital fees for obtaining the measurements should be waived (34 cases, $85.0 \%$ ). In many cases, despite a working group having been nominally organised within a hospital to drive the implementation of the preterm screening policy, there had been a lack of management follow-through (18 cases, $45.0 \%$ ). Action plans to prevent preterm births were reported to be in force at most hospitals (33 cases, $82.5 \%$ ). These were supplemented by regular meetings to clarify related tasks ( $25 / 33$ cases, $75.8 \%)$ and to review the provision of appropriate drugs and medical supplies (22/33 cases, $66.7 \%$; Table $5)$.

In line with the policies of the Ministry of Public Health for preterm birth prevention, cervical length screening was mostly performed only for high-risk groups (25 cases, 62.5\%). However, the screening was typically conducted under an unclear system, with a lack of detailed guidance documents or process flow charts (29 cases, 72.5\%). The screening was partly performed in some cases ( 26 cases, $74.3 \%$ ), or as part of a clearly defined workload (18/35 cases, $51.4 \%)$. The policy guidelines for preterm birth prevention from the Ministry of Public Health, 2017, were observed by many of the tertiary hospitals (28 cases, $70.0 \%$ ) and followed for high-risk groups (28 cases, 70.0\%). However, certain service problems were apparent, such as long waiting times (18 cases, 45.0\%) and high expense (14 cases, 35.0\%; Table 6 in appendix).

\section{(4) Process evaluation of a universal cervical length measurement programme and its barriers}

The main barriers to implementing universal cervical length screening at tertiary hospitals were reported to be heavy obstetrician workloads (20 cases, $50.0 \%$ ) and a lack of confidence in performing the measurements (20 cases, $50.0 \%$ ). Other perceived barriers included an inadequate number of medical personnel (24 cases, $60.0 \%$ ) and the lack of free drug support for preterm birth prevention in high-risk cases (29 cases, 72.5\%; Table 7). Possible ways to combat the identified barriers included (1) reducing the unnecessary or unrelated workloads of physicians (18 cases, $45.0 \%)$; (2) providing physicians with training to increase their confidence in performing cervical length measurement (22 cases, 55.0\%); and (3) providing adequate and regular funding from the relevant agencies (32 cases, $80.0 \%$; Table 8).

\section{Discussion}

All of the administrative respondents in our study were obstetricians, so they had a good understanding of the problems related to preterm births. They all worked in the field of pregnancy screening services concomitant with performing other jobs, such as teaching and conducting research. Consequently, their workloads negatively impacted on their personal ability to participate in a universal cervical length screening programme.

However, the primary responsibility of healthcare managers at tertiary hospitals in Thailand is setting hospital policies and managing their subordinates to ensure their compliance with those policies. At the same time, the experience of the healthcare managers can influence the instructions they issue to subordinates regarding the need to observe established policies as well as their specific screening recommendations(16). In particular, if the managers have personal experience with premature births, they are more likely to recommend screening.(16) Moreover, they are required to inform pregnant women 
about the risks of preterm delivery and its relationship with cervical length screening. Having more time available to describe the benefits of cervical length screening is necessary to properly assist patients to understand the importance of cervical length measurement.(17) Therefore, the healthcare managers' workloads can affect the quality of screening as well as the educational processes within their hospital.

Performing cervical length measurements by vaginal ultrasound examination is useful and has been recommended to facilitate planning of patient management.(18) In terms of the accessibility and financial aspects of implementing cervical length measurement in Thailand, the Thai Ministry of Public Health has recognised the importance of cervical length screening to prevent premature births. The appropriate policies have been prescribed, and the necessary diagnostic tools are mostly sufficient. On the other hand, there are constraints related to the overall screening skill levels of the involved medical personnel at Thai public hospitals and the staff resources available there. Implementing universal cervical length screening to prevent preterm births is not just an issue for Thailand, but is a worldwide challenge.

From our study, almost all of the hospitals at the tertiary level (39/40 cases; $97.5 \%)$ still considered preterm births to be a major problem, and the respondents were well aware of the negative impacts of preterm deliveries. Most obstetricians in Thailand can perform cervical length measurements, even without certificate approval. However, 6 out of the 40 respondents (15\%) stated they could not perform such measurements, and half (50\%) were unsure of the correct method of performing cervical length measurements. Regular training programmes to improve and maintain skill levels should therefore be provided at tertiary centres.

The Thai public health system is committed to reducing preterm births. Many efforts have been made in this regard, including the establishment of a universal policy for cervical length measurement in Thailand to screen high-risk pregnant women for preterm delivery and to supply them with progesterone to prevent preterm births. Various forms of progesterone, including vaginal suppositories, oral medications and injections, have been prepared, but typically they are not free in Thailand. A previous study(19) that supported the use of natural progesterone in pregnancies stated that the administration of the hormone was not harmful to the nervous system; instead, it could actually prevent neurological complications. It has been reported that the use of 17-alpha-hydroxyprogesterone caproate, a synthetic progesterone, may have less benefit than natural progesterone(20) and may even have negative effects on the long-term functioning of a baby's learning system.(21) Natural progesterone administered in a vaginal suppository form was found to reduce complications in newborns, with a reduced duration of hospital stay and reduction in preterm births, compared with 17-alpha-hydroxyprogesterone caproate.(20) However, further long-term studies are needed.

Our research suggests that the Maternal and Child Health Board has little active role in the execution of screening programmes at Thai public hospitals. However, if programmes were fully established at each hospital with appropriate Maternal and Child Health Board oversight of their effectiveness, the willingness of subordinates to support universal screening could be improved. 
The experience of obstetricians after examinations also affects cervical length screening. For example, pregnant women with a short cervix may have been found to have a higher rate of full term delivery than those with a normal cervix. Patients with a short cervix and who receive regular treatment may have a greater risk of preterm delivery. Recent data indicates that a cervical length screening programme followed by progesterone for those with a short cervix will reduce preterm birth rates by less than $0.5 \%$. (22) The authors in that study believed that the screening did not actually reduce the preterm birth rate and that it may not have been worth using progesterone in the indicated pregnant women. Therefore, universal cervical length measurement has not been implemented in some hospitals in Thailand and remains controversial.

From our study, cervical length measurement was opposed by about $24.1 \%$ of all respondents. This supports the previous study's finding that healthcare managers' experiences influence their policy decisions on the implementation of screening at their hospital.(16) Because of public healthcare funding constraints, some Thai hospitals do not have progesterone supplementation available for the treatment of patients with a short cervix. Hence, obstetricians at those centres may not be inclined to measure cervical lengths. Other reasons are heavy physician workloads, the length of time needed to perform the procedure and a reluctance of patients to undergo vaginal examinations. Patients may also find it inconvenient to use a vaginal drug and may prefer a weekly progesterone injection. Because of funding shortfalls, some tertiary hospitals in Thailand presently do not have both the vaginal and injected forms of progesterone available, which would make it impossible for them to provide progesterone prevention for pregnant women with a short cervix.

Cervical length measurement may not be available at all secondary hospitals. Therefore, relaxation or adjustment of the examination period should be considered to provide greater flexibility for cervical length measurement so that more people living in rural areas can have the opportunity to undergo screening. A previous sensitivity analysis suggested that universal transvaginal ultrasound cervical length screening is unlikely to be cost-effective when the prevalence of a transvaginal ultrasound cervical length of $\leq 20 \mathrm{~mm}$ falls below $0.31 \%$.(23) Establishing the prevalence of short cervixes in a population and its contribution to preterm birth is therefore important before universal screening is introduced.

Multiple studies have shown that cervical length measurement and its implementation result in fewer preterm births and improved neonatal outcomes. $(19,24)$ Cervical length measurements should be considered along with foetal anatomy screening during 19-20 weeks gestation. Abdominal ultrasound examination on a regular basis during the 18- to 20-week gestation period does not incur additional costs. Transabdominal ultrasound screening can reduce the need for transvaginal ultrasound and the subsequent costs.(25) Although up to $60 \%$ of pregnant women may still need transvaginal ultrasound, (25) there is still the problem of who will bear the responsibility for the additional costs. However, some pregnant women clearly need serial screening for cervical length measurement. An additional costeffectiveness analysis would therefore be required and is a worthy parameter to assess. 
The Maternal and Child Health Board should inform healthcare managers in the obstetrics and gynaecology units of Thai hospitals about any screening and treatment programmes. This action recognises the roles of those personnel in managing their subordinates and instructing pregnant women in the intricacies of the screening programme. Deficiencies in the knowledge of those healthcare managers in any area relevant to preterm births, defensive strategies, screening options, treatments and related interventions will reduce the prevalence of cervical length screening.(26) Additionally, if a healthcare manager does not accept the value of screening or the performance of other preventive interventions, the likelihood that a patient will receive adequate counselling will also be hampered.(27)

The research found that $62.5 \%$ of secondary hospitals only screened high-risk women or those who had a previous preterm birth. This does not match the policies of the Ministry of Public Health. The main cause of preterm births was idiopathic in $60 \%$ of cases(28); only $7 \%$ of preterm births involved mothers with previous deliveries.(29) Therefore, universal cervical length screening is necessary, and adequate training of healthcare managers in obstetrics and gynaecology units should be pursued.

Nevertheless, our research found that most healthcare managers had a good level of awareness of the problem of preterm births and were willing to work to solve this serious problem in Thailand. The implementation of a universal cervical length screening programme accessible to all pregnant women should be possible.

\section{Conclusions}

The main obstacles to implementing a cervical length measurement programme from the perspective of healthcare managers are the current heavy workloads of the staff who would be involved, and a lack of funding for the costs of ultrasound scanning and hormone therapy. The elimination of unnecessary work tasks to reduce heavy physician workloads and the provision of adequate and regular funding by relevant government agencies would greatly facilitate the implementation of a universal cervical length measurement programme in Thailand.

\section{Declarations}

\section{Ethics approval and consent to participate}

The authors have each completed the International Committee of Medical Journal Editors' form for Uniform Disclosure of Potential Conflicts of Interest. All the authors declare they have nothing to disclose. All protocols were approved by the institutional research committee (Si 480/2019), Faculty of Medicine, Siriraj Hospital, Mahidol University. All the procedures performed in studies involving human participants were in accordance with the ethical standards of the institutional research committee (Si 480/2019) and with the 1964 Helsinki declaration and its later amendments or comparable ethical standards. Written informed consent was obtained from all participants.

\section{Consent for publication}


Not applicable

\section{Availability of data and materials}

The datasets used and/or analysed during the current study available from the corresponding author on reasonable request.

\section{Competing interests}

The authors have each completed the International Committee of Medical Journal Editors' form for Uniform Disclosure of Potential Conflicts of Interest. All the authors declare they have nothing to disclose.

\section{Funding}

We thank the Faculty of Medicine Siriraj Hospital, Mahidol University for its funding support ([IO] R016233023).

\section{Authors' contributions}

VT and SC contributed to the conception and design of the research; the acquisition, analysis and interpretation of the data; the drafting and critical revision of the manuscript; and the approval of the final manuscript.

SA contributed to revision of the manuscript and the approval of the final manuscript.

AK contributed to the transcription of data from the audio recordings and the approval of the final manuscript.

JP contributed to the analysis and interpretation of the data, critical revision of the manuscript and the approval of the final manuscript.

PTcontributed to the drafting and critical revision of the manuscript; and the approval of the final manuscript.

\section{Acknowledgement}

We appreciate the administrative support provided by Nattacha Palawat.

\section{References}

1. American College of Obstetricians and Gynecologists.Preterm (premature) Labor and birth. Retrieved 2016 Oct 1, from: http://www.acog.org/Patients/FAQs/PretermPrematurelabor-and-birth.

2. American College of Obstetricians and Gynecologists. ACOG practice bulletin no. 127: Management of preterm labor. Obstet Gynecol 2012;119(6):1308-17. doi: 10.1097/AOG.0b013e31825af2f0. 
3. March of Dimes, The Partnership for Maternal, Newborn \& Child Health, Save the Children, WHO. Born too soon: the global action report on preterm birth. Geneva: World Health Organization; 2012 (http://whqlibdoc.who.int/publications/2012/9789241503433_eng. pdf, accessed 13 October 2014).

4. Risnes KR, Vatten LJ, Baker JL, Jameson K, Sovio U, Kajantie E et al. Birthweight and mortality in adulthood: a systematic review and meta-analysis. Int J Epidemiol. 2011;40:647-61. doi:10.1093/ije/dyq267.

5. Larroque B, Bertrais S, Czernichow P, Leger J. School difficulties in 20-yearolds who were born small for gestational age at term in a regional cohort study. Pediatrics. 2001;108:111-15.

6. United Nations Children's Fund and World Health Organization, Low Birthweight: Country,regional and global estimates. UNICEF, New York, 2004.

7. World Health Organization. Global targets 2025. To improve maternal, infant and young child nutrition (,accessed 17 October 2014).

8. Colatat T. Situation of preterm birth: The maternal and childhealth network2005. Available from: http://www.tmchnetwork.com/node/163.

9. Society for Maternal-Fetal Medicine Publications Committee with the assistance of Vincenzo Berghella. Progesterone and preterm birth prevention: translating clinical trials data into clinical practice. Am J Obstet Gynecol. 2012;206(5):376-86.

10. Committee on Practice Bulletins-Obstetrics, ACOG. Practice bulletin no. 130: prediction and prevention of preterm birth. Obstet Gynecol. 2012;120(4):964-73.

11. National Institute for Health and Care Excellence. Preterm labor and birth. NICE guideline. 2015. [Internet]. Available from: https://www.nice.org.uk/ guidance/ng25. Accessed January 9, 2018.

12. Figo Working Group On Best Practice In Maternal-Fetal M, International Federation of G, Obstetrics. Best practice in maternal-fetal medicine. Int J Gynaecol Obstet. 2015;128(1):80-2.

13. American College of Obstetricians and gynecologists. Use of progesterone to reduce preterm birth Commitee Opinion No.419.Washington.DC: American College of Obstetricians and Gynecologists;2008.

14. Mackenzie R, Walker M, Armson, A, Hannah, ME. Progesterone for the prevention of preterm birth among women at increased risk: a systematic review and meta-analysis of randomized controlled trials. Am J Obstet Gynecol 2006;194(5):1234-42.

15. Policy of preterm birth prevention for Thailand 2017. Ministry of Public Health; 2017.

16. Feeley TH, Cooper J, Foels T, Mahoney MC. Efficacy expectations for colorectal cancer screening in primary care: identifying barriers and facilitators for patients and clinicians. Health Commun. 2009;24(4):304-15.

17. Kazemier BM, Miller ES, Grobman WA, Mol BW. Variation in preterm birth rate and the role of short cervical length across two populations: a comparative cohort study. J Perinatol. 2016;36(7):516-21.

18. Romero R, Nicolaides KH, Conde-Agudelo A, O'Brien JM, Cetingoz E, Da Fonseca E, et al. Vaginal progesterone decreases preterm birth $</=34$ weeks of gestation in women with a singleton 
pregnancy and a short cervix: an updated meta-analysis including data from the OPPTIMUM study. Ultrasound Obstet Gynecol. 2016;48(3):308-17.

19. Norman JE, Marlow N, Messow CM, Shennan A, Bennett PR, Thornton S, et al. Vaginal progesterone prophylaxis for preterm birth (the OPPTIMUM study): a multicentre, randomised, double-blind trial. Lancet. 2016;387(10033):2106-16.

20. Saccone G, Khalifeh A, Elimian A, Bahrami E, Chaman-Ara K, Bahrami MA, et al. Vaginal progesterone vs intramuscular 17alpha-hydroxyprogesterone caproate for prevention of recurrent spontaneous preterm birth in singleton gestations: systematic review and meta-analysis of randomized controlled trials. Ultrasound Obstet Gynecol. 2017;49(3):315-21.

21. Willing J, Wagner CK. Exposure to the Synthetic Progestin, 17alpha-Hydroxyprogesterone Caproate During Development Impairs Cognitive Flexibility in Adulthood. Endocrinology. 2016;157(1):77-82.

22. Norman JE. Progesterone and preterm birth. Int J Gynaecol Obstet. 2020;150(1):24-30.

23. Werner EF, Hamel MS, Orzechowski K, Berghella V, Thung SF. Cost-effectiveness of transvaginal ultrasound cervical length screening in singletons without a prior preterm birth: an update. Am J Obstet Gynecol. 2015;213(4):554 e1-6.

24. Werner EF, Han CS, Pettker CM, Buhimschi CS, Copel JA, Funai EF, et al. Universal cervical-length screening to prevent preterm birth: a cost-effectiveness analysis. Ultrasound Obstet Gynecol. 2011;38(1):32-7.

25. Friedman AM, Srinivas SK, Parry S, Elovitz MA, Wang E, Schwartz N. Can transabdominal ultrasound be used as a screening test for short cervical length? Am J Obstet Gynecol. 2013;208(3):190 e1-7.

26. Lim AC, Goossens A, Ravelli AC, Boer K, Bruinse HW, Mol BW. Use of progesterone treatment for the prevention of recurrent preterm birth: identification of obstacles to change. Am J Perinatol. 2010;27(3):241-9.

27. Ramos M, Esteva M, Almeda J, Cabeza E, Puente D, Saladich R, et al. Knowledge and attitudes of primary health care physicians and nurses with regard to population screening for colorectal cancer in Balearic Islands and Barcelona. BMC Cancer. 2010;10:500.

28. Goldenberg RL. The management of preterm labor. Obstet Gynecol. 2002;100(5 Pt 1):1020-37.

29. Khalifeh A, Berghella V. Universal cervical length screening in singleton gestations without a previous preterm birth: ten reasons why it should be implemented. Am J Obstet Gynecol. 2016;214(5):603 e15 .

\section{Tables}


Personal information (can answer more than 1 choice)

\section{Details of personal information}

Number

(\%)

$(n=40)$

Age (years) (mean \pm SD [range])

$50.2 \pm$

$5.6(38$,

60)

Years since graduation with degree in medicine (mean \pm SD [range])

$26.4 \pm$

$5.7(14$

36)

Graduated with Diploma in Obstetrics and Gynaecology (n [\%])

40

$(100.0 \%)$

Graduated with Diploma in Maternal and Foetal Medicine (n [\%])

$0(0.0 \%)$

Years working in the field of obstetrics and gynaecology (mean \pm SD [range])

$21.0 \pm$ $7.2(5$,

35)

Years working in the position as head of department/unit of obstetrics and gynaecology (median [range])

Total bed-capacity of the hospital $(\mathrm{n}[\%])$

$\cdot 300-500$

$\cdot>500$

26

Duties other than administrative work (n [\%])

- Teaching

- Service

- Research

$\cdot 11$

- Other work (healthcare accreditation quality development, social security, welfare cooperative, social medicine, mediation centre, head of Cancer Registry Provincial Maternal and Child Health District, National Health Security Office subcommittee, auditor of medical records) $\cdot 8$ $(20.0 \%)$ 
Table 2

Context evaluation of tertiary hospitals (can answer more than one choice)

\section{Relevant content}

Number

(\%)

$(n=40)$

Concrete policy of cervical length screening to prevent preterm births

$\cdot 16$

- Have a specific operating policy

$(40.0 \%)$

- Have an operating policy in conjunction with other jobs

$\cdot 13$

$(32.5 \%)$

- No policy

$\cdot 11$

$(27.5 \%)$

An executive would have a role to play in setting up a preterm birth prevention policy

- Yes

$\cdot$ No

$\cdot 1$

An executive can direct subordinate doctors to follow the policy

- 35

- Yes

- No

Encouragement provided by the Maternal and Child Health Board to implement a cervical

- Yes

- No

Resources provided by the Maternal and Child Health Board to implement a programme of preterm-birth prevention

- Micronised progesterone vaginal soft-gel capsules (Utrogestan)

- $0(0 \%)$

- Progesterone pessaries (Cyclogest)

-17-OHPC (Proluton Depot)

- Funding for the training of medical personnel in cervical length measurement

- Funding to buy an ultrasound machine

- Other 


\section{Relevant content}

Number

(\%)

$(n=40)$

Role of the Maternal and Child Health Board in the cervical length screening programme to prevent preterm births

$\cdot 7$

$(17.5 \%)$

$\cdot 25$

$(62.5 \%)$

- Little role

- Very active

$\cdot 8$

$(20.0 \%)$

Roles of the Maternal and Child Health Board that you would like to see or receive:

$\cdot 32$

$(80.0 \%)$

- Act as a policymaker and provide the main operational plan for the district hospital in order to ensure all hospitals operate in the same way and to allow comparisons of the performance of each hospital

$\cdot 20$

- Be the leader or take personal responsibility for the academic training programme for cervical length screening for staff in district hospitals

- 26 $(65.0 \%)$

- 1

(2.5\%)

- Other 
Table 3

Availability of resources

\begin{tabular}{|c|c|}
\hline Resources & $\begin{array}{l}\text { Number } \\
(\%) \\
(n=40)\end{array}$ \\
\hline Hospital provides adequate obstetricians to cover the regular workloads & $\cdot \overrightarrow{9}+(22.5 \%)$ \\
\hline $\begin{array}{l}\cdot \text { Not enough } \\
\cdot \text { Enough }\end{array}$ & $\cdot 31$ \\
\hline Hospital has obstetricians who can accurately perform cervical length measurements & • $0(0 \%)$ \\
\hline • None & $\cdot \cdot 18$ \\
\hline $\begin{array}{l}\cdot \text { - Yes, but not enough } \\
\cdot \text { Yes, enough }\end{array}$ & $\cdot 22$ \\
\hline $\begin{array}{l}\text { Hospital has a person responsible for information on the preterm birth prevention } \\
\text { programme (Project Manager) }\end{array}$ & $\cdot 32$ \\
\hline - Yes & $\cdot \stackrel{8}{(20.0 \%)}$ \\
\hline $\begin{array}{l}\text { Hospital has specific funding for cervical length measurement screening } \\
\text { - Yes (funding is obtained from the district budget allocations) } \\
\text { - No }\end{array}$ & $\begin{array}{l}\cdot 1 \\
(2.5 \%) \\
\cdot 39 \\
(97.5 \%)\end{array}$ \\
\hline $\begin{array}{l}\text { Hospital has enough ultrasound machines for routine tasks } \\
\text { - Not enough } \\
\text { - Enough }\end{array}$ & $\begin{array}{l}\cdot 12 \\
(30.0 \%) \\
\cdot 28 \\
(70.0 \%)\end{array}$ \\
\hline $\begin{array}{l}\text { Hospital has enough ultrasound machines that can be used specifically for a cervical } \\
\text { length measurement screening programme }\end{array}$ & $\begin{array}{l}\cdot 20 \\
(50.0 \%)\end{array}$ \\
\hline $\begin{array}{l}\cdot \text { Not enough } \\
\text { - Enough }\end{array}$ & $\begin{array}{l}\cdot 20 \\
(50.0 \%)\end{array}$ \\
\hline
\end{tabular}


Table 4

Assessment of the project inputs

Input evaluation

Number

(\%)

$(n=40)$

Realisation that premature births are a problem at the hospital

- 39

- Yes

- No

- 1

Degree of severity of the problem (overview of all factors)

- Low

- Moderate

$\cdot 15$

• High

Physicians can perform cervical length measurements by vaginal ultrasound

- Yes (with a certificate of approval)

- You (without a certificate)

- No

Usefulness of cervical length measurement to prevent preterm births

- Useless

- Mildly useful

- Very useful

If cervical length measurements to prevent preterm births are considered very useful:

- Establish a policy for the hospital to carry out specific tasks

- Establish a policy for hospitals to perform the measurements in conjunction with other $(40.0 \%)$ tasks

- Not required to be defined as a hospital policy, but can be screened as a doctor requirement

- Other

Does universal cervical length screening reduce preterm births

- Yes, it reduces the rate of preterm births.

- No, it does not affect the rate of preterm births. 


\begin{tabular}{|lc|}
\hline Input evaluation & $\begin{array}{l}\text { Number } \\
(\%)\end{array}$ \\
& $(\mathbf{n}=\mathbf{4 0})$ \\
\hline $\begin{array}{ll}\text { Knowledge of the policy of implementing a universal cervical measurement system for } \\
\text { premature birth prevention as laid out in the 2017 policy guidelines of the Ministry of }\end{array}$ & $(72.5 \%)$ \\
Public Health & $\cdot 11$ \\
• Know & $(27.5 \%)$ \\
- Don't know & \\
If you know the policy: do you agree with this policy $(n=29) ?$ & $(62.1 \%)$ \\
- Agree & $\cdot 7 / 29$ \\
- Disagree & $(24.1 \%)$ \\
- Other & $\cdot 4 / 29$ \\
& $(13.8 \%)$ \\
\hline
\end{tabular}


Table 5

Impact of preterm births on the pregnant women, family and the hospital

Effects on the pregnant women, family and on the hospital

Number

(\%)

$(n=40)$

Workload of the personnel involved

$\cdot 0$

- No effect

$\cdot 4$

- Little effect

$(10.0 \%)$

- Heavy effect

Expenses that the hospital has to bear

- No effect

- Little effect

- 5

- Heavy effect

Length of hospital stays

- No effect

- Little effect

- Heavy effect

Family expenses

- 1

- No effect

- Little effect

- Heavy effect

Problems in caring for the newborn

- No effect

- Little effect

- Heavy effect

Problems in the life and work of the family.

- No effect

- Little effect

- Heavy effect 
The policy of universal cervical length screening by the Ministry of Public Health can solve relevant problems and impacts from preterm birth; do you agree?

- Yes

- No

- No idea

Universal cervical length screening should be charged to all pregnant women; do you agree?

- Yes

- No

Has a working group or committee been established for the implementation of preterm birth prevention at your hospital?

- There is a clear working group

- Only some personnel have been appointed

- No appointments have been made

- Other

- Yes

- No

If an action plan has been established $(n=33)$, which of these apply?

- There are monthly/quarterly/yearly operational planning meetings

- There are meetings to report the performance monthly/quarterly/yearly

- There are occasional meetings or activities 


\section{Effects on the pregnant women, family and on the hospital}

Number

(\%)

$(n=40)$

In the event that an action plan has been established $(n=33)$, which of these apply?

- A meeting was organized to clarify the guidelines for preterm birth prevention

- Short-term academic training was provided to relevant personnel

- Doctors were sent for training in related specialty and subspecialty fields

- Action plans have been formulated for the procurement of materials, general equipment and screening equipment

- Drug and medical supplies are provided

- There are assessment indicators for community hospitals (the Maternal and Child Health Board will revise and support provision of drugs to community hospitals) $\cdot 25 / 33$

$(75.8 \%)$

$\cdot 12 / 33$

$(36.4 \%)$

$\cdot 10 / 33$

$(30.3 \%)$

$\cdot 13 / 33$

$(39.4 \%)$

$\cdot 22 / 33$

(66.7\%)

$\cdot 1 / 33$

(3.0\%) 
Table 6

Process evaluation of the universal cervical length screening programme

Process evaluation

Number

(\%)

$(n=40)$

According to the policy of the Ministry of Public Health, what is the current situation

$\cdot 10$

regarding the implementation of cervical length screening to prevent preterm births at the hospital

- Screening is performed in every case

$\cdot 25$

$(62.5 \%)$

- Screening is performed in high-risk cases

- No screening tests are performed

What is the condition of the guidelines for cervical length screening to prevent preterm births that have been established by the hospital?

$\cdot 6$

$(15.0 \%)$

$\cdot 29$

$(72.5 \%)$

- 5

$(12.5 \%)$

- No guidelines have been established

In the case of systematic guidelines or prepared documents being provided, does real practice follow those guidelines and documents? $(n=35)$

- No

- Practice follows some parts, or only some of the time

$\cdot 26$

$(74.3 \%)$

- All requirements are strictly followed

$\cdot 8$

$(22.9 \%)$

In the case of systematic guidelines or prepared documents being provided, were personal $\quad(n=35)$ responsibilities set? $(n=35)$

- Yes

- 18

$(51.4 \%)$

- No

- 17

$(48.6 \%)$

Is the hospital currently taking action to prevent preterm births as per the Ministry of Public Health's guidelines for Thailand, 2017?

$\cdot 28$

$(70.0 \%)$

- Yes - action has been implemented

$\cdot 12$

- NO - action has not yet been implemented 


\begin{tabular}{|c|c|}
\hline Process evaluation & $\begin{array}{l}\text { Number } \\
(\%) \\
(n=40)\end{array}$ \\
\hline $\begin{array}{l}\text { Were any problems encountered when screening was performed in the target group } \\
\text { (pregnant women who are at risk)? }\end{array}$ & $\begin{array}{l}\cdot 28 \\
(70.0 \%)\end{array}$ \\
\hline - No & $\begin{array}{l}\cdot 12 \\
(30.0 \%)\end{array}$ \\
\hline Which problems were encountered? & $\begin{array}{l}\cdot 18 \\
(45.0 \%)\end{array}$ \\
\hline - Long waiting times & $\begin{array}{l}\cdot 3 \\
(7.5 \%)\end{array}$ \\
\hline - Cost & $\begin{array}{l}\cdot 14 \\
(35.0 \%)\end{array}$ \\
\hline - Shyness/fear of examination/fear of pain & $\begin{array}{l}\cdot 12 \\
(30.0 \%)\end{array}$ \\
\hline follow-up appointments, inconvenient to do the exam) & $\cdot 3$ \\
\hline
\end{tabular}


Table 7

Possible barriers to implementing universal cervical length screening in the hospitals

\section{Possible barriers}

Number

(\%)

$(n=40)$

Problems related to the physicians

$\cdot 11$

- Insufficient number of doctors available

$(27.5 \%)$

- Doctors have other urgent and necessary tasks to perform

$\cdot 20$

$(50.0 \%)$

- Doctors have excessive routine tasks to perform

- Doctors do not think that premature births are so serious a problem that this scheme is required

- Doctors do not think that cervical length screening can play a role in preventing preterm births

- Doctors do not believe that cervical length screening is worth the labour and financial investment needed

- Doctors are unsure about the correctness of the method of performing cervical length measurements

- Other (pregnant women receiving late antenatal care, physicians were unable to perform the measurement and were non-practiced, did not know the policy)

Problems related to other personnel, such as nurses/staff

- Insufficient number of personnel available

- There are other tasks that are needed and more urgent

- Already have excessive routine tasks to perform

- Uncertain or concerned about the accuracy of non-medical personnel in collecting,

Problems related to the hospital

- Hospital administrators ignore the issue

- Lack of operational funding from government agencies

- Lack of free drug support for preventing preterm births among pregnant women with

- Other (training programme is not provided for obstetricians, lack of continuous follow-up 
Table 8

Possible ways to overcome the obstacles

\section{Possible ways}

Number

(\%)

$(n=40)$

Relevant to the physicians and/or related persons

$\cdot 11$

$(27.5 \%)$

- Add/ask for more doctors who have the potential to screen cervical lengths by various methods

- Provide training to physicians on a regular basis to ensure they can confidently perform cervical length measurements

- Provide knowledge and skills training on performing cervical length measurements for doctors who perform routine work until they are confident in the examination and are certificated

$\cdot 21$

$\cdot 21$

- Provide reliable research results/performance/examples of screening results, and

18 demonstrate the cost-effectiveness of the implementation to doctors/nurses and other stakeholders, to facilitate realisation of the need for the procedure/programme

- Reduce unnecessary and unrelated workloads of doctors

Relevant to the hospitals

- Must receive adequate and regular funding from relevant agencies

- Ensure widespread operational potential and readiness at community hospitals

- Provide patient education on the benefits of cervical length measurements to prevent preterm births

- Other (providing adequate ultrasound machines and medication for prevention in highrisk cases) 


\section{Possible ways}

Number

(\%)

$(n=40)$

Is there a monitoring system and evaluation process in place to assess the results of the universal cervical length screening to address the above-mentioned aspects?

$\cdot 13$

- No

$\cdot 18$

$(45.0 \%)$

- Some aspects are in place, as specified below $(n=18)$

- Objectives

$\cdot 7 / 18$

$(38.9 \%)$

- Monitoring system

$\cdot 7 / 18$

- Evaluation of screening results

- Treatment evaluations

$\cdot 4 / 18$

$(22.2 \%)$

- Assessments of the incidence of preterm births after the project

$\cdot 8 / 18$

$(44.4 \%)$

- Yes, all aspects

$\cdot 9 / 18$

$(50.0 \%)$

$\cdot 9$

$(22.5 \%)$ 